\title{
Foreign Language Classroom Anxiety among Iraqi Students and its Relation With Gender and Achievement
}

\author{
Taha Talib Ali (Corresponding author) \\ School of Language Studies and Linguistics, FSSK, Universiti Kebangsaan Malaysia, Malaysia \\ E-mail: Taha2000vip@yahoo.my \\ Wong Fook Fei \\ School of Language Studies and Linguistics, FSSK, Universiti Kebangsaan Malaysia, Malaysia \\ E-mail: wff@ukm.my
}

Received: 11-08-2016

Published: 02-01-2017
Accepted: 09-10-2016

doi:10.7575/aiac.ijalel.v.6n.1p.305
Advance Access Published: November 2016

URL: http://dx.doi.org/10.7575/aiac.ijalel.v.6n.1p.305

\begin{abstract}
Language anxiety is always seen as debilitative factor that deters learners from successfully learning a foreign language. Although many studies have been reported on foreign language learners' anxieties, little research, if any, has been undertaken on Iraqi postgraduate EFL learners. The objective of the present study is threefold: a) to investigate the factors contributing to foreign language classroom anxiety among Iraqi postgraduate EFL students, b) to investigate the difference between both genders in the level of anxiety and c) to investigate the relationship between the level of anxiety and the academic achievement of the students based on GPA. The study employed a mixed mode approach using survey questionnaire (AFLAQ)and semi-structured interview. The study reported that three factors such as communication apprehension, negative evaluation and test anxiety are anxiety-arousing factors with test anxiety has the greatest contribution. The study also reported that females show more anxiety compared to males. It was also shown that there is a negative correlation between language anxiety and academic achievement which means that students with high level of FL anxiety tend to yield lower grades and vice-versa.
\end{abstract}

Keywords: Arabic Foreign Language Anxiety Questionnaire (AFLAQ), Anxiety factors, Gender differences, Academic achievement

\section{Introduction}

Students encounter many problems during the process of learning a second or foreign language. These problems vary and can be classified according to their sources into three factors. These factors are teacher factor, language factor and learner factor (Brown, 2007). The focus of this study is on the third factor which is learner factor. Learner factors have been investigated extensively by many researchers who have investigated even the psychological aspects of the learners. There are many areas related to the psychological aspects of EFL/ESL learners, and the main focus of the earlier studies was on the cognitive variables such as learning styles, intelligence and aptitude. The studies which came later tended to focus on the emotional factors because such factors have a direct influence on the learning process in the sense that they might either debilitate or facilitate the process of second or foreign language learning (Nahavandi \& Mukundan, 2013). The psychological aspects of the learners have attracted many researchers because they are essential for the development of the process of teaching and learning a second or foreign language. Brown (2007) stated that the process of second language learning and teaching will not be understood or improved without taking into consideration the psychological factors of the learners as they have a direct influence on language learning. One of the EFL/ESL learners' psychological aspects, which attracted researchers, is anxiety and many researchers in this area have investigated its influence on the process of language learning (Cheng, 2004; Horwitz, 2001; Nahavandi \& Mukundan, 2013; Oda, 2013).

\section{Statement of the Problem}

Iraqi university EFL students experience high level of anxiety which creates potential problems in the process of learning English as a foreign language (Oda 2013). According to MacIntyre \& Dewaele. (2014), anxiety interferes with acquisition, retention, and production. Thus, the process of input, processing and output are extremely affected by anxiety which means that anxiety might have a negative influence on the overall process of learning a second or a foreign language. Therefore, there is a need for more investigation of the issue of anxiety among Iraqi EFL students and the factors related to it in order to help the students overcome this problem.

In addition, the relationship between the level of anxiety and gender is still a controversial issue that has been conducted in different settings (Aslan, 2009; Shi et al., 2006). To the best knowledge of the researcher, there is only one study that investigated this issue among Iraqi EFL learners who are currently staying in Malaysia which is Keong \& Jawad (2015) 
and it was limited to speaking anxiety. There is a need to investigate the relationship between foreign language classroom anxiety and gender among Iraqi EFL learners in order to reveal whether there are differences between students in the level of anxiety in terms of gender.

Based on many studies, the problem of anxiety is not limited to a specific group of students as it is experienced even by the students who have achieved a high level of proficiency (Tanveer, 2007; Ezzi, 2013). However, the problem of anxiety among Iraqi EFL students still needs further investigation because studies conducted in this area are scarce. Moreover, very little research, if any, have been undertaken on anxiety among Iraqi EFL postgraduate students staying in Malaysia. Therefore, the present study is carried out to address the problem and bridge the gap.

\section{Review of Literature}

In the field of foreign language anxiety (FLA), Spielberger (2010:1) defined anxiety as "the subjective feeling of tension, apprehension, nervousness, and worry associated with an arousal of the autonomic nervous system". In addition, Horwitz (2001) stated that "just as anxiety prevents some people from performing successfully in science or mathematics, many people find foreign language learning, especially in classroom situations, particularly stressful". To measure anxiety in the context of foreign language classroom, Horwitz et al. (1986) have created the Foreign Language Classroom Anxiety Scale (FLCAS) and reported that FLA anxiety in the classroom is explained by three factors such as communication apprehension, negative evaluation and test anxiety.

In the current study, the relationship between gender and anxiety were examined in relation to specific speaking and communication activities in the second language class, and to learners' self-perceptions of their oral skills and proficiency in English language. Some past studies, albeit with inconsistent findings, have suggested that gender could be a possible source of anxiety among EFL learners (Aslan, 2009; Zgutowicz, 2009; Wilson, 2006). There is no clear cut results regarding who experience more anxiety male or female as different variables, such as culture, play a major role in this regard (Brown, 2007). In this context, Aslan (2009) showed that different genders use different language learning strategies which will influence their achievement in English. The findings of the study revealed that the use of language learning strategies are positively effective in success in English, that females were significantly more successful than males in terms of achievement tests, and that they used more language learning strategies in learning English. Depending on the statistical results, it is discovered that there is a significant connection between gender, language learning strategies and achievement in English.

The relationship between anxiety and achievement was extremely investigated. A seminal study using the FLCAS was conducted by Horwitz et al. (1986) found that there was a significant negative correlation between FLA and students' achievement which means that students who had higher levels of anxiety gained lower scores. Correspondingly, Chee et al. (2014) also reported that there was a significant negative correlation between language anxiety and students' performances on vocabulary learning tasks. Many studies have been conducted on language anxiety and its relation to gender and academic achievement (Nahavandi \& Mukundan, 2013; Oda, 2013). However, the problem of anxiety among Iraqi EFL students still needs further investigation because research conducted in this area is scarce. Also, very little research, if any, has been undertaken on anxiety among Iraqi EFL postgraduate students. Hence, a study with mixed mode approach is required to address both the breadth and depth of this issue. Therefore, the present study is carried out to address the problem and bridge the gap.

\section{Research Objectives and Questions}

The purpose of this study is to investigate foreign language classroom anxiety among Iraqi postgraduate students in three Malaysian Universities namely UKM, UPM and UM. More specifically, it aims to investigate the factors contributing to foreign language classroom anxiety among Iraqi university EFL students, identify the differences between both genders in the level of anxiety and examine the relationship between the level of anxiety and the academic achievement of the students. While focusing on the core subject matter, this study also attempts to answer the following research questions:

1. What are the factors that contribute to foreign language classroom anxiety among Iraqi university EFL students?

2. Do males or females have higher level of foreign language classroom anxiety?

3. What is the relationship between the level of anxiety and the academic achievement of Iraqi university EFL students (based on GPA)?

\section{Method}

This study utilized both quantitative and qualitative methods. Hence, the questionnaire has been used to collect the quantitative data, while the interviews were carried out to collect qualitative data. In the current study, the quantitative approach is the primary method of data collection.

\subsection{The Sample of The Study}

The participants of the present study were Iraqi postgraduate EFL students of the English Department, Faculty of Arts in three Malaysian universities: Universiti Kebangsaan Malaysia (UKM) Universiti Putra Malaysia (UPM) and Universiti Malaya (UM), during 2014-2015 academic year. Fifty students (26 males and 24 females) ranging between 24 to 35 years were involved in this study. The study used a convenience sampling method involved 50 students since 
the researcher of the present study had access to only 50 students. Furthermore, this number could meet the requirement of survey which is 30 plus (Creswell, 2013). Moreover, the current study only focused on the postgraduate students because there are a very few Iraqi students studying at undergraduate level in Malaysian universities. The participants were selected from UKM (25), UPM (16) and UM (9) proportionately since the Iraqi students studying in UKM outnumbered the other universities. All of the students were Iraqis, which suited the purpose of the study, to explore the language anxiety from the perspective of students who share a similar culture and background.

\subsection{Instruments}

This study utilizes an instrument developed by Al-Saraj (2014). The instrument was originally based on the most popular scale known as Foreign Language Classroom Anxiety (FLCA) which was conducted by Horwitz et al. (1986). In this regard, Al-Saraj (2014) has developed an Arabic scale which is called Arabic Foreign Language Anxiety Questionnaire (AFLAQ). The development of the questionnaire was originally based on the information gathered from Saudi Arabian students while learning a foreign language. The items in this questionnaire are extremely similar to those in the FLCAS based on the belief that adopting existing terminologies and items would facilitate comparisons across cultures which were not available in FLCA. Beside the use of the questionnaire survey, individual interviews were also conducted with 6 students to provide deep insights into potential sources of language anxiety from students' perspectives. Thus, the interview aims to triangulate the research questions to ensure that the issues identified in this study reflect and represent the culture of the participants.

\section{Results}

To identify factors that contribute to foreign language classroom anxiety among Iraqi postgraduate EFL students, one way ANOVA was carried out to test the difference between several samples. In addition, mean score was used in order to find out which factor contributes most to language anxiety. Finally, an appropriate statistical test named Pearson Coefficient Correlation was also conducted to assess the relationship between dimension of the level of anxiety and the academic achievement based on GPA.

Table 1. One way ANOVA to test difference among factors

\begin{tabular}{llllll}
\hline & Sum of Squares & df & Mean Square & F & Sig. \\
\hline Between Groups & 2432.6 & 2 & 1216.3 & 42.9 & .000 \\
\hline Within Groups & 4163.7 & 147 & 28.3 & & \\
\hline Total & 6596.4 & 149 & & \\
\hline
\end{tabular}

As shown in Table 1, there is a significant statistical difference between the three factors of foreign language classroom anxiety $(\mathrm{F}=42.9, \mathrm{P}=0.000<.05)$. Consequently, we can conclude that communication apprehension, negative evaluation and test anxiety have significant impact on foreign language classroom anxiety among Iraqi university EFL students.

Table 2. Comparison between males and females in terms of FLCA

\begin{tabular}{llllll}
\hline Gender & & $\mathrm{N}$ & Mean & SD & Std. Error Mean \\
\hline Communication apprehension & Female & 24 & 31.2 & 5.5 & 1.1 \\
\cline { 2 - 6 } & Male & 26 & 26.8 & 5.4 & 1.1 \\
\hline Negative evaluation & Female & 24 & 23.1 & 3.3 & 0.66 \\
\cline { 2 - 6 } & Male & 26 & 21.6 & 2.6 & 0.50 \\
\hline Test anxiety & Female & 24 & 33.2 & 6.3 & 1.3 \\
\cline { 2 - 6 } & Male & 26 & 28.4 & 6.4 & 1.3 \\
\hline
\end{tabular}

Table 3 shows the mean and standard deviation for FLCA value as per gender. According to this findings, Iraqi females have scored higher mean in all factors. As can be observed, females with the values of communication apprehension $(\mathrm{M}=31.2, \mathrm{SD}=5.5)$; negative evaluation $(\mathrm{M}=23.1, \mathrm{SD}=3.3)$ and test anxiety $(\mathrm{M}=33.2, \mathrm{SD}=6.3)$ have higher level of $\mathrm{FL}$ classroom anxiety in comparison with males with the values of communication apprehension $(\mathrm{M}=26.8, \mathrm{SD}=5.4)$, negative evaluation $(M=21.6, S D=2.6)$ and test anxiety $(M=28.4, S D=6.4)$, respectively.

Table 3 makes it clear that females are more anxious than males. Test anxiety is found to be extremely contributing factor to FL classroom anxiety. Females are more concerned about the consequences of failing the course. Hence, fear of failing the course is one of the most anxiety-provoking source that incites test anxiety among students. In line with AFLAQ statement number 24 "I fear failing my foreign language class", Student 2 said: "In fact, one of the most debilitative things that makes me feel nervous during the exam is the feeling of failing the exam". Based on the above mentioned explanations, the sense of fear of failing the exam was clearly huge. Collectively, males and females have 
also reported other sources of anxiety during the exam including misspelling of some words, given time, level of difficulty, readiness, format of test, and grammar. Such factors were well expressed by student 5 "During exam, I face many things which make me anxious including time, score and the format of the question". Under those circumstances, these factors evoke the feeling of anxiety which result in forgetting the exam materials. Thus, the students are generally concerned about the possibility of repeating or failing the course.

Another factor contributing to language anxiety is communication apprehension. Respondents showed that speaking inside classroom is the biggest challenge that are caused them apprehensive. A related anxiety-arousing source associated to communication apprehension is the fear of being called upon by a teacher in class. This factor is usually accompanied by fear of mispronunciation, different accent between the speaker and hearer, misunderstanding, low proficiency and formal situation. In this regard, Student 3 showed his remarks "When I speak inside the classroom, I feel too worried about my pronunciation and also about my grammatical rules". Interestingly, females have elaborated another anxiety-arousing factor connected to communication apprehension which is "giving presentation". The issue of giving presentation as expressed by Students 1,4 and 6 is accompanied by fear of standing in front of the class, maintaining eye contact, inability to deliver the message and fear of the questions that might be asked.

In relation to negative evaluation, respondents have expressed their feeling differently. The students explained that they remain passive most of the time as they are afraid of committing mistakes in the language during the process of communication. For example, Student 4 believes that, due to her self-image, she may avoid talking with others. Another student acknowledged that he always thinks of the others in class while speaking. In the same context, Student 1 admits that she is afraid of being mocked by others and thus she prefers to keep silent. Moreover, she claimed that different pronunciation makes her anxious and thus her self-image could be threatened. Collectively, the respondents have expressed their fear of negative evaluation mostly by attributing it to potential classmates interpretation, language error and jeopardizing their self-image. As explained, although both males and females reported that they have fear of negative evaluation while speaking with others, it was found that females show more apprehension while speaking in front of the others.

Table 3. Correlation matrix of the research variables

\begin{tabular}{lllll}
\hline & $(1)$ & $(2)$ & $(4)$ & $(5)$ \\
\hline Communication apprehension & 1 & & & \\
\hline Negative evaluation & $.321^{* *}$ & 1 & & \\
\hline Test anxiety & $.793^{* *}$ & $0.330^{*}$ & 1 & 1 \\
\hline GPA & $-.562^{* *}$ & 0.050 & $-.469^{* *}$ & \\
\hline
\end{tabular}

*Correlation is significant at the 0.05 level (2-tailed).

**Correlation is significant at the 0.01 level (2-tailed)**

The relationship between the level of anxiety and academic achievement was achieved through an appropriate statistical test named Pearson Coefficient Correlation to assess the relationship between dimensions of the level of anxiety and the academic achievement of Iraqi university EFL students (based on GPA). According to the results presented in Table 3, there is a negative correlation among the level of communication apprehension $(\mathrm{r}=-0.562, \mathrm{P}<0.01)$ and test anxiety $(\mathrm{r}=-$ $0.469, \mathrm{P}=0.000$ ) and GPA. Which means that the higher the level of anxiety is, the more likely the students receive low grades and vice-versa.

\section{Discussion}

There are different factors behind the prevalent feeling of anxiety among Iraqi learners. These factors are varied according to learners' psychology and gender. The learner psychology represented in three factors which are known as communication apprehension, fear of negative evaluation and test anxiety. These variables constitute a major contribution to provoke anxiety while learning English (Horwitz, 2001; Alqahtani, 2011; Al-Khairy, 2013).

Test anxiety was found to be the major cause of anxiety among Iraqi EFL learners. Test anxiety is considered a significant factor that extremely demotivates various aspect of EFL learning process (Aida, 1994; Aydin, 2009; Petridou \& Williams, 2007). The results obtained from the research study by Aydin et al. (2006) are in accordance with the current findings which claim that test anxiety had a big contribution to language anxiety among students compared to the factors of communication apprehension and negative evaluation. Correspondingly, Joanna et al. (2003) argued that test anxiety negatively affects students' motivation which in turn prevents students from reflecting their actual performance in test. Hence, it is important for lecturers to be aware of this issue and try to ease the students concerns when conducting tests and also try to diversify tests formation and methods (Keong et al., 2014).

Another predominant factors contributing to classroom anxiety among Iraqi students were communication apprehension and negative evaluation. Respondents showed that speaking inside classroom is an extremely challenging issue which led them to feel apprehensive and anxious. Notably, females were reported to be more apprehensive and sometimes feel more hesitant to interact with classmates. Correspondingly, some studies support this finding which claimed that females experience more anxiety than male who appear to be more reluctant to report about their anxiety in comparison with their female counterparts (Abu-Rabia, 2004; MacIntyre, 2005; Williams and Andrade, 2008). Moreover, a 
conventionally male dominant society, Korean female students were also more anxiety ridden than males, and they tend to avoid social interaction probably because they were brought up in Korea (Park et al., 2013). However, some studies argued that males experience more anxiety (Awan et al., 2010; Kitano, 2001). Hence, culture might play a crucial role in determining level of anxiety among Iraqi females. As a collectivistic county, Iraq is considered as a conservative country where extra bounds and ties are put on females which in turn might contribute to provoke the feeling of anxiety and lack of confidence (Brown, 2007).

Considering students' achievement, the study also found that there is a negative correlation between anxiety level and students' achievement. Students' GPA were used to determine their academic achievement and it was reported that there was a negative correlation between anxiety and students achievement. Accordingly, anxiety was argued to have an impact on students' academic achievement (Batumlu and Erden, 2007). Therefore, it can be claimed that the results of the present study is in line with Al-Shuaibi et al. (2014) whose study suggested that learners with a low GPA are more probable to experience high level of classroom anxiety compared to those with a higher levels of GPA. However, the relationship between anxiety level and achievement are still controversial issue. Thus, some studies reported that there is a negative correlation between anxiety level and students' achievement (Awan et al., 2010; Batumlu and Erden, 2007; Al-Shuaibi et al., 2014), while other claimed the opposite (Hamzah, 2007). Nonetheless, some studies reported that there is no significant correlation between anxiety and student performance (Capan \& Simsek, 2012).

It can be concluded that females were more anxious in all domains compared to males. Certain psychological trait such as shyness, low self-esteemed and apprehension have significantly contributed to students' classroom anxiety. In addition, language anxiety and students' achievement were also strongly correlated, which means that students with high level of anxiety are more likely to get low grades. The results seem to primarily support previous studies (AlShuaibi et al., 2014; MacIntyre, 2005; Elkhafaifi, 2005; Abu-Rabia, 2004)

\section{Conclusion}

The study found that three factors such as communication apprehension, test anxiety and negative evaluation have contributed to the Iraqi postgraduate EFL students' language anxiety, while test anxiety has the major contribution. The study reported that the females experience more anxiety than males in the English classroom. The study also showed that the level of anxiety and academic achievement are negatively correlated. However, although the result of the present study shows that there is a negative relationship between academic achievement and anxiety, which is consistent with the findings of some studies in the literature, other studies contradict with the findings of this study. Hence, replication of the current study is needed to see to what extent the result would reflect and confirm the findings of the study.

\section{References}

Aida, Y., (1994). Examination of Horwitz, Horwitz, and Cope's construct of foreign language anxiety: The case of students of Japanese. The Modern Language Journal, 78, 155-168.

Alrabai, F. (2015). The influence of teachers' anxiety-reducing strategies on learners' foreign language anxiety. Innovation in Language Learning and Teaching, 9(2), 163-190.

Al-Khairy, M. H. (2013). English as a foreign language learning demotivational factors as perceived by Saudi undergraduates. European Scientific Journal, 9, 365-382.

Alqahtani, M. (2011). An investigation of the language needs of Saudi students studying in British postgraduates programmes and the cultural differences impacting on them (Unpublished $\mathrm{PhD}$ thesis). University of Southampton, Southampton, UK.

Al-Saraj, T. M. (2014). Revisiting the foreign language classroom anxiety scale (FLCAS): The anxiety of female English language learners in Saudi Arabia. L2 Journal, 6(1).

Al-Shuaibi, J., Hamdan-Mansour, A. M., \& Azzeghaiby, S. N. (2014). Foreign language anxiety among students studying foreign languages. Life Science Journal, 11(8).

Aslan, O. (2009). The Role of Gender and Language Learning Strategies in Learning English. Master's Thesis, Middle East Technical University.

Awan, R.-u.-N., Azher, M., Nadeem, M., \& Naz, A. (2010). An Investigation of Foreign Language Classroom Anxiety and Its Relasionship with Students' Achievement. Journal of College Teaching and Learning, 7(11), 33-40.

Aydin, S. (2009). Test anxiety among foreign language learners: A review of literature. Journal of Language and Linguistic Studies, 5, 127-137.

Aydin, S., Yavuz, F., \& Yesilyurt, S. (2006). Test anxiety in foreign language learning. Balikesir University. Journal of Social Sciences Institute, 9, 145-160.

Batumlu, D. Z., \& Erden, M. (2007). The Relationship Between Foreign Language Anxiety and English Achievement of Yildiz Technology University School of Foreign Learners Preparatory Students. Journal of Theory and Practice in Education, 3(1), 24-38.

Brown, H. D. (2007). Principles of language learning and teaching. New York: Pearson. 
Chee Keong, Y., Yassin, A. A., \& Abdulrahman, T. T. A. (2014). Oral Communication Problems of Yemeni High School EFL Students in Malaysia. Journal of Applied Sciences, 14(24), 3620.

Cheng, Y. S. (2004). A measure of second language writing anxiety: Scale development and preliminary validation. Journal of Second Language Writing, 13(4), 313-335.

Creswell, J. W. (2013). Research design: Qualitative, quantitative, and mixed methods approaches. Sage publications.

Ezzi, N. A. A. (2012). The impact of gender on the foreign language anxiety of the Yemeni university students. International Journal of Applied Linguistics \& English Literature, 1(2), 65-75.

Hamzah, M. H. 2007. Language anxiety among first year Malay students of the international Islamic college: an investigation of 12 skills, sources of anxiety, and L2 performance. A Master Dissertation in Human Science, IIUM, Malaysia.

Horwitz, E. (2001). Language anxiety and achievement. Annual review of applied linguistics, 21, 112-126.

Horwitz, E. K., Horwitz, M. B., \& Cope, J. (1986). Foreign language classroom anxiety. The Modern language journal 70(2): 125-132.

Joanna, H., Hernandez, S., \& Margaret, R. (2003). Decreasing anxiety and frustration in the Spanish language classroom. Retrieved from ERIC database (ED474368).

Keong, Y. C., \& Jawad, H. F. (2015). Iraqi EFL Postgraduate Students Anxiety in Speaking English at a Malaysian University. International journal of education and research. 3, 2

Lee, Mei-L. (2011). Differences in the Learning Anxieties Affecting College Freshman Students of EFL. In R. Jaidev, M. L. C. Sadorra, W. J. Onn, L. M. Cherk, \& B. P. Lorente (Eds.), Global Perspectives, Local Initiatives (1st ed., pp. 169-182). National University of Singapore: Centre for English Language Communication.

Liu, M., \& Huang, W. (2011). An exploration of foreign language anxiety and English learning motivation. Education Research International, 1-8

MacIntyre, P. D. (2002). Motivation, anxiety and emotion in second language acquisition. Individual differences and instructed language learning, 2, 45-68.

MacIntyre, P. D., \& Gardner, R. C. (1994). The subtle effects of language anxiety on cognitive processing in the second language. Language learning, 44(2), 283-305.

MacIntyre, P., \& Dewaele, J. M. (2014). The two faces of Janys? Anxiety and enjoyment in the foreign language classroom. Studies in Second Language Learning and Teaching, 4(2), 237-274.

Nahavandi, N., \& Mukundan, J. (2013). Foreign Language Learning Anxiety among Iranian EFL learners Along Gender and Different Proficiency Levels. Language in India, 13(1), 133-161.

Oda, A. H. (2013). Investigating the factors that cause language anxiety in Iraqi EFL learners. Journal of Basrah Researches, 38(2), 25-53.

Park, G. P., \& French, B. F. (2013). Gender differences in the foreign language classroom anxiety scale. System, 2(41), 462-471.

Petridou, A., \& Williams, J. (2007). Accounting for aberrant test response patterns using multilevel models. Journal of Educational Measurement, 44, 227-247. http://dx.doi.org/10.1111/j.1745-3984.2007.00036.x

Shi, Y. Z., \& LIU, Z. Q. (2006). Foreign Language Reading Anxiety and Its Relationship to English Achievement and Gender [J]. Journal of Pla University of Foreign Languages, 2, 013.

Spielberger, C. D. (2010). State-Trait anxiety inventory. John Wiley \& Sons, Inc.

Tanveer, M. (2007). Investigation of the factors that cause language anxiety for ESL/EFL learners in learning speaking skills and the influence it casts on communication in the target language. Unpublished doctoral dissertation. University of Glasgow.

Williams, K. E., \& Andrade, M. R. (2008). Foreign language learning anxiety in Japanese EFL university classes: Causes, coping, and locus of control. Electronic Journal of Foreign Language Teaching, 5(2),181-191.

Zgutowicz, R. (2009). What effects does language anxiety have on ESL students' decisions to speak English in a middle school classroom? Master's Thesis, Hamline University, Minnesota. 